\title{
Delta is a ventral to dorsal signal complementary to Serrate, another Notch ligand, in Drosophila wing formation
}

\author{
Dan Doherty, Georg Feger, ${ }^{1}$ Susan Younger-Shepherd, Lily Yeh Jan, and Yuh Nung Jan ${ }^{2}$ \\ Howard Hughes Medical Institute and the Departments of Physiology and Biochemistry, University of California, San \\ Francisco, California 94143-0724 USA; ${ }^{1}$ Gesellschaft für Analyse-Technik und Consulting mbH, 78467 Konstanz, Germany
}

\begin{abstract}
Wing margin formation in Drosophila requires the Notch receptor and, in the dorsal compartment, one of its ligands, Serrate. We provide evidence that Delta, the other known ligand for Notch, is also essential for this process. Delta is required in ventral cells at the dorsal/ventral compartment boundary, where its expression is specifically elevated in second-instar wing discs during wing margin formation. Moreover, ectopic Delta expression induces wingless, vestigial, and cut and causes adult wing tissue outgrowth in the dorsal compartment. This effect is mediated by Notch, because loss of Notch activity suppresses Delta-induced ectopic wing outgrowth. Whereas ectopic expression of Notch or the truncated activated Notch induces cut in both dorsal and ventral compartments, ectopic Delta expression induces cut only in the dorsal compartment and ectopic Serrate induces cut only in the ventral compartment. These observations indicate that Notch-expressing cells in a given compartment have different responses to Delta and Serrate. We propose that Delta and Serrate function as compartment-specific signals in the wing disc, to activate Notch and induce downstream genes required for wing formation.
\end{abstract}

[Key Words: Delta; Notch; Serrate; Drosophila; wing patterning; compartment-specific signaling]

Received October 2, 1995; revised version accepted January 17, 1996.

Cell-cell communication is a fundamental process required for patterning and growth during Drosophila wing development (for review, see Whittle 1990; Blair 1995). The wing develops from a cluster of undifferentiated cells called the wing imaginal disc. The disc cells are set aside during embryogenesis, proliferate during larval development, and by late third larval instar, the disc has developed the basic pattern elements of the mature wing. Within the epithelial monolayer of the disc, dorsal and ventral compartment cells lie in two adjoining regions (Fig, 2C, below). During pupal development, the dorsal cells become apposed to the ventral cells as the disc folds and everts along the dorsal/ventral $(\mathrm{D} / \mathrm{V})$ boundary to form the mature wing blade that is comprised of two symmetrical cell layers. The $\mathrm{D} / \mathrm{V}$ boundary becomes the wing margin, marked with sensory bristles along the anterior margin and large noninnervated hairs along the posterior margin.

The wing consists of four compartments (anterior, posterior, dorsal, and ventral $\}$ as defined by lineage restriction studies (Garcia-Bellido et al. 1973; Blair 1993). Tissue excision and transplantation experiments have demonstrated that juxtaposition of cells from different regions of developing appendages induces proliferation and intercalation of pattern elements (for review, see

${ }^{2}$ Corresponding author.
French et al. 1976). More recently, it has been proposed that interaction between cells with different compart.mental identities is required for the normal growth and patterning of the wing and other appendages (Meinhardt 1983; Diaz-Benjumea and Cohen 1993; Tabata and Kornberg 1994).

A number of genes involved in signaling between dorsal and ventral compartment cells have been identified. Dorsal but not ventral cells express apterous $\langle a p\rangle$, a homeo domain transcription factor that is required for wing disc proliferation and formation of the wing margin (Bourgouin et al. 1992; Diaz-Benjumea and Cohen 1993; Williams et al. 1993). The fringe (fng) gene, which encodes a novel, putatively secreted molecule, is expressed in the dorsal compartment under the control of ap (Irvine and Wieschaus 1994). Juxtaposition of fng-expressing and fng-nonexpressing cells induce tissue outgrowth and the formation of wing margin structures, suggesting that the fng signal can only be received by cells that do not express fng. To explain that both fng $^{-}$and $f n g^{+}$cells at the borders of $\mathrm{fng}^{-}$clones are transformed into wing margin, Irvine and Wieschaus (1994) proposed that fng is a dorsal to ventral signaling molecule that induces a reciprocal (ventral to dorsal) signal from the $f^{-} g^{-}$cells to the $f_{n g}{ }^{+}$cells. The existence of a reciprocal signal was also proposed by Williams et al. (1994) to explain the similar behavior of ap clones. 
Candidates for the ventral to dorsal signal include wingless $\{w g\rangle$, a member of the Wnt gene family, which encodes a secreted protcin and is essential for wing development, as well as many other developmental processes in Drosophila |for review, see Klingensmith and Nusse 1994; Siegfried and Perrimon 1994|. Loss-of-function wg mutations result in abnormal wing phenotypes, ranging from loss of wing margin bristles to complete absence of wing tissue, depending on the particular combination of alleles (Phillips and Whittle 1993; for review, see Lindsley and Zimm 1992). In second-instar wing discs, wg is expressed in the ventral compartment and may function to maintain the restriction of $a p$ expression to the dorsal compartment (Williams et al. 1993). Both $w g$ and $a p$ functions are required for the expression of the vestigial $(\mathrm{vg}$ ) enhancer lac $Z$ reporter construct, the earliest molecular marker for the wing margin (Williams et al. 1994). Later, during third instar, wg expression is restricted to a stripe at the $\mathrm{D} / \mathrm{V}$ boundary in cells that later form the wing margin. These results indicate that $w g$ is required early for proliferation and/or patterning of the disc and later for formation of wing margin structures.

The Notch $(N)$ signaling pathway is also essential for wing development. Loss-of-function mutations in $N$ cause loss of wing tissue similar to that observed in $w g$ mutants. $N$ encodes a large transmembrane receptor necessary for communication in a number of developmental processes. During neurogenesis, the $N$ gene product, in concert with its ligand Delta \{Dl\}, functions to single out neural precursors from fields of neuroectodermal cells (for review, see Campos-Ortega 1988; Ghysen et al. 1993; Artavanis-Tsakonas et al. 19951. This process requires cell-cell communication among groups of cells, all of which can both send and receive signals (Heitzler and Simpson 1991\}. Strong genetic interactions between $N$ and $w g$ indicate that the two genes function in the same pathway during wing margin formation (Couso and Martinez Arias 1994; Hing et al. 1994). Couso and Martinez-Arias $\{1994\}$ have proposed models in which wg acts upstream or parallel to $N$ during wing margin development and may even be an N ligand; however, loss of $N$ function on either side of the $\mathrm{D} / \mathrm{V}$ boundary causes loss of $w g$ expression, wing margin, and wing blade tissue in both compartments (de Celis and Garcia-Bellido 1994; Rulifson and Blair 1995/, suggesting a function for $N$ upstream of $w g$.

Kim et al. (1995) and Diaz-Benjumea and Cohen (1995) have proposed that Serrate (Ser), an N ligand with sequence similarity to Dl (Fleming et al. 1990; Rebay et al. 1991), functions as a dorsal to ventral signal downstream of fng. Ser expression is restricted to the dorsal compartment in the second-instar wing disc. Loss of Ser function in dorsal cells at the $\mathrm{D} / \mathrm{V}$ boundary results in loss of wing margin, whereas ectopic expression of Ser in both the dorsal and ventral compartments induces adult wing tissue outgrowth and $w g$ expression only in the ventral compartment (Speicher et al. 1994; Kim et al. 1995).

The mild wing notching observed with temperaturesensitive combinations of $D I$ alleles has implicated $D l$ in wing development, although its role has remained unclear (Parody and Muskavitch 1993). We demonstrate that $D l$ is required for wing development and can induce a number of genes required for wing formation including $w g, v g$, and cut. We propose that $D l$ encodes a ventral to dorsal signal, because $D I$ is required in ventral cells at the $\mathrm{D} / \mathrm{V}$ boundary and ectopic $\mathrm{Dl}$ induces cut expression and adult wing outgrowth only in the dorsal compartment. In contrast, ectopic Ser induces cut expression only in the ventral compartment, indicating that $N$-expressing cells can have different responses to the two $\mathrm{N}$ ligands. These results suggest that $D l$ plays an equivalent but complementary role to Ser as a compartmentspecific signal in the genetic program for wing margin development.

\section{Results}

Loss of $\mathrm{Dl}$ function during wing development causes loss of wing tissue

As part of the $N$ signaling pathway, $D l$ plays an important role in several developmental processes (for review, see Muskavitch 1994!. Using a temperature-sensitive allele of D1, Parody and Muskavitch (1993) have shown that $D I$ is required during late second and early third instar for wing margin formation. Exposure of such $D l$ mutant flies to the restrictive temperature at this developmental stage leads to notching at the distal tip of the wing, similar to the phenotype seen in flies heterozygous for an $N$ null mutation. To further analyze the role of $D I$ in wing development, we generated clones homozygous for a loss-of-function $D I$ allele, $D I^{\text {rev10 }}$ (Heitzler and Simpson 1991), by X-irradiating second-instar larvae. We found that $D I$ is required for wing margin formation in the ventral but not the dorsal compartment. Ventral clones that abutted the $\mathrm{D} / \mathrm{V}$ boundary caused gaps in the wing margin (Fig. $1 E_{t} F_{i}$ Table 1 ), whereas clones that abutted the boundary from the dorsal side and those within the wing blade in either compartment did not cause gaps in the wing margin |Fig. 1C,D|. The loss of wing margin phenotype is nearly identical to that caused by clones lacking Ser (Fig. 1B; Speicher et al. 1994; DiazBenjumea and Cohen 1995). Clones were identified using forked as a marker (Diaz-Benjumea and Cohen 1993) and by scoring hypertrophy of the wing veins caused by loss of $D l$ function (Fig. 1C,F; Parody and Muskavitch 1993). Loss of sensory bristles on the anterior wing margin and the noninnervated posterior wing margin hairs was caused by both dorsal and ventral clones that included the domains of cells that give rise to these cuticle structures. All clones, both dorsal and ventral, also caused hypertrophy of vein tissue when they overlapped the normal position of wing veins. The phenotypes in bristle differentiation and wing vein formation are consistent with the known functions for $D$ l (Parks and Muskavitch 1993; Parody and Muskavitch 1993). The absence of large portions of the wing in $D l$ mosaics indicates that $D l$ is required for formation of the wing margin as well as the proliferation and/or viability of wing blade cells. The 

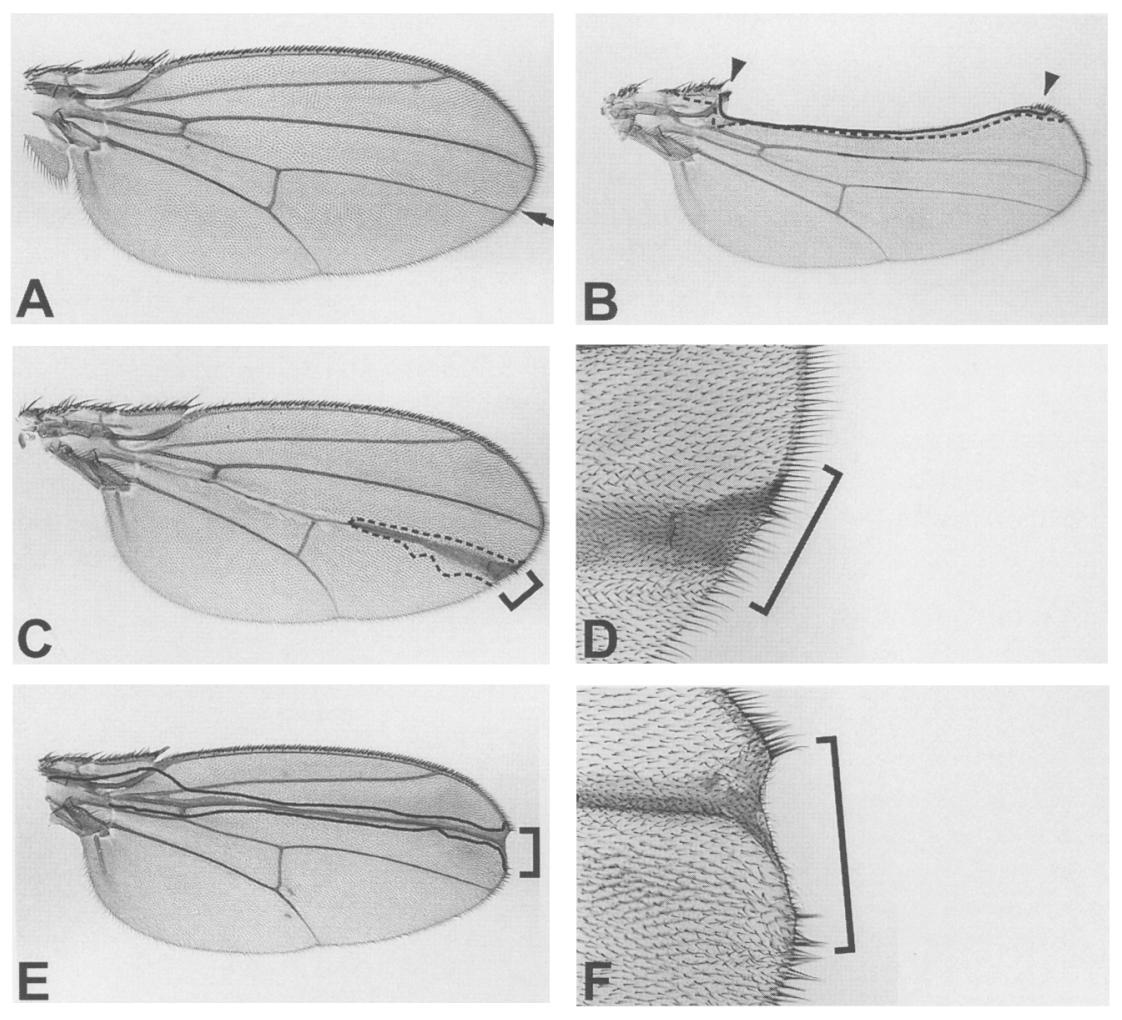

Figure 1. Ventral but not dorsal $D P^{\text {rev10 }}$ clones that abut the $\mathrm{D} / \mathrm{V}$ boundary cause loss of wing margin. All wings are oriented with anterior up, proximal to the left. Broken lines mark clone boundaries in the dorsal compartment, whereas solid lines mark clone boundaries in the ventral compartment. (A) Unirradiated control $f^{36 a} ; D P^{\text {rev10 }}$ e/bld ou $f^{+98 B}$ wing. The $\mathrm{A} / \mathrm{P}$ compartment boundary between veins 3 and 4 is marked by an arrow. $(B)$ Wing with a $D P^{\text {rev10 }}$ that crosses the $D / V$ boundary; the anterior wing margin and a large part of the wing blade are missing. Black arrowheads mark groups of forked ebony bristles at the clone borders. (C) Wing with a D $I^{\text {Tevio }}$ clone that abuts the $\mathrm{D} / \mathrm{V}$ boundary from the dorsal side (bracket), whereas the dorsal marginal hairs are missing and the wing margin and blade are intact. $(D)$ High-magnification view of $C$. $[E]$ Wing with a $D$ Trev10 $^{\text {rew }}$ clone that abuts the $\mathrm{D} / \mathrm{V}$ boundary from the ventral side (bracket); there is a gap in the wing margin and adjacent wing blade. (F) High-magnification view of $E$. compartment-specific requirement for $D 1$ is the first indication that $D l$ encodes a ventral to dorsal signal reciprocal to the dorsal to ventral Ser signal (Diaz-Benjumea and Cohen 1995; Kim et al. 1995).

\section{Loss of $\mathrm{Dl}$ function during wing development alters wg expression}

Because our mosaic studies indicated that $D I$ plays an important role in wing development, we used wg expression as a marker to examine how loss of $D I$ function in mitotic clones affected formation of the $\mathrm{D} / \mathrm{V}$ boundary. $w g$ is expressed in the ventral compartment of secondinstar wing discs and then along the $\mathrm{D} / \mathrm{V}$ boundary from early third instar onward (Baker 1988; Couso et al. 1993;
Williams et al. 1993). Adult viable wg alleles cause loss of the entire wing and occasional wing to notum transformations (for review, see Lindsley and Zimm 1992); however, reduced $w g$ activity during third instar causes loss of wing margin structures only (Phillips and Whittle 1993).

We generated homozygous $D I^{r e v 10}$ clones in secondinstar wing discs and examined wg protein expression in these discs at late third instar using an anti-wg antibody (van den Heuvel et al. 1989). We identified clones by the absence of heat shock-induced expression of a nuclear Myc marker on the $\mathrm{Dl}^{+}$third chromosome (see Materials and methods|. wg expression was altered when mu* tant clones intersected the $\mathrm{D} / \mathrm{V}$ boundary. In large clones, we consistently observed a reduction in wg ex-

Table 1. Dl is required only in the ventral compartment for wing margin formation

\begin{tabular}{lccccc}
\hline Location of clone $^{\mathrm{a}}$ & $\begin{array}{c}\text { Total } \\
\text { clones }^{\mathrm{b}}\end{array}$ & $\begin{array}{c}\text { Only dorsal } \\
\text { bristles absent }\end{array}$ & $\begin{array}{c}\text { Only ventral } \\
\text { bristles absent }\end{array}$ & $\begin{array}{c}\text { Dorsal and ventral } \\
\text { bristles absent } \\
\text { [no gap) }\end{array}$ & $\begin{array}{c}\text { Gap in margin } \\
\text { and blade }\end{array}$ \\
\hline Dorsal & 11 & 11 & 0 & 0 & 0 \\
Ventral & 10 & 0 & $2^{\mathrm{c}}$ & 0 & 8 \\
Dorsal and ventral & 31 & 0 & $1^{\text {d }}$ & 2 & 28 \\
Internal (dorsal or ventral) & 14 & 0 & 0 & 0 & 0 \\
\hline
\end{tabular}

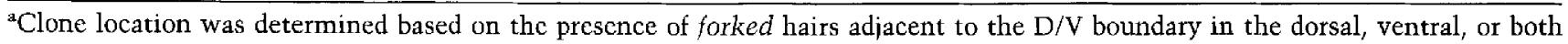
compartments; forked hairs were confined to the wing blade in internal clones.

bonly wings with a $D l$ wing vein phenotype were analyzed; six wings with clones were unscorable owing to gross distortion of the wing tissue.

${ }^{\mathrm{c}}$ Wings with clones that appear to abut the boundary because they eliminate ventral bristles.

${ }^{\mathrm{d}}$ Wing with both dorsal and ventral forked hairs; wing margin and dorsal bristles unaffected. 
pression at the $\mathrm{D} / \mathrm{V}$ boundary in homozygous $D 1^{\text {rev } 20}$ cells that were surrounded by other homozygous $D$ l $^{\text {revio }}$ cells (not shown). At the borders of narrower clones, in the homozygous $D P^{\text {revio }}$ cells that were adjacent to heterozygous $D 1^{\text {rev7o }}$ cells, $\mathrm{D} / \mathrm{V}$ boundary wg expression was elevated and ectopic wg cxpression extended into the ventral compartment (Fig. 2A,B). The separation between wg and Myc expression is attributable to the membrane association of $w g$ and nuclear localization of Myc. Rarely, low levels of ectopic wg expression extended for short distances into the dorsal compartment along the inside border of clones. These results suggest that D1, like fng (Irvine and Wieschaus 1994), can induce wg expression at the border between Dl-expressing and Dl-nonexpressing cells.
$\mathrm{D}$ l expression is elevated at the $\mathrm{D} / \mathrm{V}$ boundary in second-instar wing discs

The effect of $\mathrm{DI}^{-}$clones on $w g$ expression raises the question of whether $D 1$ plays an early role in setting up the D/V boundary; so we examined $D l$ expression in wing discs during second and third instar when proliferation and wing margin formation occur. To characterize $D l$ expression with respect to the dorsal and ventral compartments, we stained discs expressing an ap-lacZ enhancer trap, which marks cells of the dorsal compartment (Diaz-Benjumea and Cohen 1993), with antibodies to $\beta$-galactosidase and Dl (Kooh et al. 1993). The earliest patterned Dl protein expression appeared during midsecond-instar. The highest levels of Dl were centered
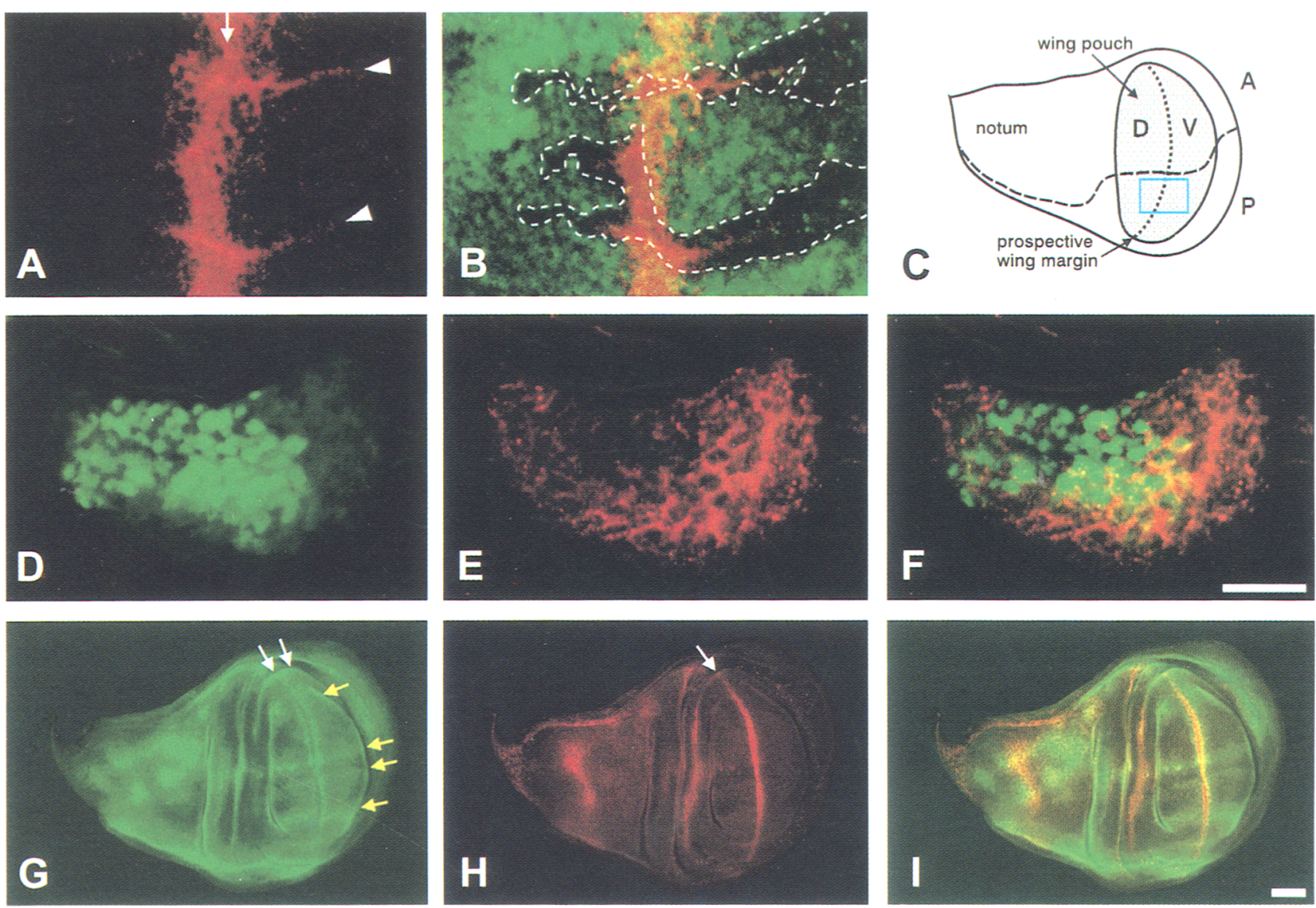

Figure 2. $D I^{-}$clones and wild-type $\mathrm{Dl}$ expression in the wing disc. $(A, B)$ Homozygous $D I^{\text {tev10 }}$ clones in a third-instar wing disc (box in $C$ marks the region of the disc in the images). (A) wg expression (red). The arrow marks the endogenous stripe of wg expression at the $\mathrm{D} / \mathrm{V}$ boundary, whereas the arrowheads mark ectopic wg expression. $(B)$ Overlay of $A$ with the Myc epitope tag signal (green); the homozygous $D 1^{\text {rev } 10}$ clones (broken lines) are marked by the absence of Myc signal. Ectopic wg is present approximately one cell width from the nuclei of myc-expressing cells. $(C)$ Fate map of wing disc (Bryant 1975) adapted from Diaz-Benjumea and Cohen (1993); the box marks the region shown in $\mid A, B)$. $(D-F\rangle) \mathrm{Dl}$ protein and ap-lacZ expression in a mid-second-instar wing disc. Dorsal is to the left. Scale bar, $8 \mu \mathrm{m}$. $|D|$ ap-lacZ (green) is expressed in the nuclei of dorsal compartment cells. $\{E|D|$ protein (red) is expressed in the membranes of cells at the D/V boundary and mainly in the ventral compartment. $|F|$ Overlay of $D$ and $E$. $\{G-I \mid \mathrm{Dl}$ and wg expression in a wild-type third-instar wing disc. In all wing dise figures anterior is up, dorsal is to the left. Scale bar, $50 \mu \mathrm{m}$. (G) Endogenous Dl (green) is expressed in two stripes of cells along the prospective wing margin (white arrows), the prospective wing veins (yellow arrows), and in proneural clusters. $(H)$ Endogenous $\mathrm{wg}$ (red) is expressed in the prospective wing margin (white arrow) and in a band across the notum. (I) Overlay of $G$ and $I I$. The wg stripe is flanked by the Dl stripes. 
along the $\mathrm{D} / \mathrm{V}$ boundary, as marked by the limit of the ap-lacZ domain (Fig. 2D-F). High levels of $\mathrm{Dl}$ protein were also present in the ventral compartment of the wing pouch, with lower levels in the dorsal compartment. $\mathrm{Dl}$ was absent from the region of the disc that forms the dorsal notum. In early third-instar wing discs there was a small amount of punctate $\mathrm{Dl}$ staining in a narrow stripe of cells at the $\mathrm{D} / \mathrm{V}$ boundary (not shown). Finally, at late third instar, $\mathrm{Dl}$ expression was highest in two stripes flanking the wg-expressing cells at the D/V boundary, as well as in the prospective wing veins and proneural clusters (Kooh et al. 1993; Fig. 2G-I). The $D I$ expression pattcrn is consistent with $D l$ having an early role in setting up the wing margin and a later role in maintaining the wing margin and patterning the wing margin bristles.

\section{Ectopic expression of $\mathrm{Dl}$ results in abnormal outgrowth of dorsal wing tissue}

Having found that $\mathrm{Dl}$ is required for wing margin formation, we examined whether ectopic $D l$ expression could induce an ectopic wing margin or wing tissue outgrowth. Using the GAL4 system (Brand and Perrimon 1993), we cctopically expressed a UAS-D1 transgene in the wing disc with the patched-GAL4 enhancer trap line G559.1 (ptcG4) (Hinz et al. 1994). We refer to the combination of $p t c \mathrm{G} 4$ with UAS-DI as ptcG4-Dl. ptcG4 is expressed strongly in a stripe along the anterior/posterior $\langle\mathrm{A} / \mathrm{P}\rangle$ border of the wing disc by mid third instar, with the highest level at the sharp posterior border and gradually lower levels toward the more irregular anterior border (see Materials and methods; Kim et al. 1995). The GAL4 system has been reported to give more extreme ectopic expression phenotypes at higher temperatures iSpcicher et al. 1994). When raised at $29^{\circ} \mathrm{C}$, all of our UAS-D1 lines were lethal in combination with ptcG4. At $22^{\circ} \mathrm{C}$, one line $\left|\mathrm{UAS}-\mathrm{Dl}^{30 \mathrm{A1}}\right|$ produced viable ptcG4-Dl adults with disrupted anterior cross veins. Shifting ptcG4-Dl $1^{30 A 1}$ larvae to $29^{\circ} \mathrm{C}$ for $24 \mathrm{hr}$ during second instar resulted in adult flies with striking wing outgrowth. The abnormal wing tissue outgrowth occurred only on the dorsal side of the wing blade (Fig. $3 \mathrm{~A}-\mathrm{C})$; patches of large bristles characteristic of the anterior double row or posterior wing margin were present at the distal tip of each outgrowth. We found even more extreme outgrowth in the wings of ptcG4-Dl ${ }^{30 \mathrm{~A} 1}$ pharate adults raised at $29^{\circ} \mathrm{C}$ throughout development. Other UAS-DI insertions crossed to ptcG4 yielded pharate adults with extreme wing outgrowth even when raised at $22^{\circ} \mathrm{C}$. These pharate adults also displayed severe defects in the legs, heads, nota, and male genitalia. Thus, ectopic expression of $D$ l can induce wing outgrowth and a new wing margin, as well as defects in other tissues.

\section{Ectopic $\mathrm{Dl}$ acts through $\mathrm{N}$}

$\mathrm{Dl}$ has been shown to signal through the $\mathrm{N}$ receptor during neuronal precursor selection, and this signaling is sensitive to levels of both $N$ and $D 1$ (Vaessin et al. 1987;
Heitzler and Simpson 1991). To determine whether ectopic $\mathrm{Dl}$ also utilizes the $N$ signaling pathway for induction of wing tissue outgrowth, we asked whether outgrowth depended on wild-type $N$ function. We used the $N^{t s}$ mutation to reduce $N$ activity; raising the temperature to $29^{\circ} \mathrm{C}$ for $24 \mathrm{hr}$ during late second- and early thirdinstar larval development resulted in notching of the wing characteristic of the $N$ mutant phenotype (Fig. 3D; Shellenbarger and Mohler 1978). Shifting second-instar ptcG4-Dl male larvae that carried the $N^{t s}$ mutation to $29^{\circ} \mathrm{C}$ for $24 \mathrm{hr}$ suppressed completely the wing outgrowth phenotype, whereas control ptcG4-Dl flies that were $\mathrm{N}^{+}$or heterozygous for $N^{t s}$ displayed a strong outgrowth phenotype (Fig. 3C).

Further evidence that ectopic Dl functions through $\mathrm{N}$ is that ectopic $\mathbf{N}$ expression also induces hairs characteristic of the wing margin, similar to the phenotype of ptcG4-Dl flies raised at $25^{\circ} \mathrm{C}$. We ectopically expressed wild-type UAS $-N$ (gift from P. Simpson, Institute of Genetics and Molecular and Cellular Biology, Centre de Recherche National Scientifique (CNRS), Strasbourg, Francel by crossing it to ptcG4 (ptcG4-N). ptcG4-N flies raised at $29^{\circ} \mathrm{C}$ throughout development had a short row of ectopic hairs along the fourth wing vein on both the dorsal and ventral sides of the wing blade, reminiscent of anterior double row or posterior wing margin hairs /Fig. $3 \mathrm{E}, \mathrm{F})$; these flies occasionally displayed mild wing tissue outgrowth (data not shown). Taken together, these data confirm that ectopic $\mathrm{Dl}$ acts through $\mathrm{N}$, its known receptor, to induce abnormal wing outgrowth.

\section{Ectopic expression of $\mathrm{Dl}$ induces $\mathrm{wg}, \mathrm{vg}$, and cut expression}

Our mosaic studies indicated that $D l$ may be able to induce wg expression at the border between $D l$-expressing and Dl-nonexpressing cells. To examine this possibility further, we looked for ectopic wg expression in third-instar ptcG4 $\mathrm{Dl}$ wing discs. wg was induced mainly along the posterior border of the ectopic Dl stripe and rarely at lower levels along the anterior border. In the dorsal compartment, wg was induced in the cells just inside and just outside the posterior border of the ptcG4Dl stripe, whereas in the ventral compartment, wg was induced at a lower level and only outside the stripe (Fig. $4 \mathrm{~A}-\mathrm{Cl}$. Induction of $w g$ was not limited to lines that expressed GAL4 at the A/P boundary; lines driving UAS-Dl expression at other locations within the wing pouch also induced $w g$ expression and disc tissue outgrowth but not adult wing outgrowth (data not shown). We did not observe wg induction outside the wing pouch, suggesting that there are region-specific factors that modulate the ability of $\mathrm{Dl}$ to induce $w g$ expression.

In third-instar wing discs, ectopic $\mathrm{Dl}$ expression also induced cut, vg, deadpan (dpn), and big brain $(b i b)$ in cells along the ptcG4 stripe (Fig. $4 \mathrm{D}, \mathrm{E}$; additional data not shown). Whereas all four of these genes are normally expressed in the prospective wing margin/Williams et al. 1991; Bier et al. 1992; Blochlinger et al. 1993; D. 
Doherty et al.

Figure 3. Ectopic wing margin formation and wing tissue outgrowth induced by ectopic Dl is suppressed by $N^{t s}$. $|A|$ Wing from a ptcG4-Dl fly shifted to $29^{\circ} \mathrm{C}$ for $24 \mathrm{hr}$ during the late second and early third larval instars. Wing outgrowth with hairs characteristic of the wing margin always occurs on the dorsal side of the wing (bracket). $(B)$ High-magnification view of $A$, showing the hairs at the distal tip of the outgrowth. $\{C \mid$ Wing from a $N^{\mathrm{ts}} / \mathrm{yw}$; ptcG4/ + UAS-Dl/ + female shifted to $29^{\circ} \mathrm{C}$ for $24 \mathrm{hr}$ during the late second and early third larval instars. Note the DI-induced outgrowth with hairs characteristic of the wing margin at the tip (bracket). (D) Wing from a $N^{t s} / \mathrm{Y}$; ptcG4/+; UAS-Dl $/+$ male shifted to $29^{\circ} \mathrm{C}$ for $24 \mathrm{hr}$ during the late second and early third larval instars. The DI-induced ectopic outgrowth is completely suppressed (cf. C). Notches in the distal wing (arrowheads) are due to the reduction in $\mathrm{N}$ activity (sce text). (E) Wing from a ptcG4-N fly shifted to $29^{\circ} \mathrm{C}$ for all of the second and third larval instars. Ectopic margin-like hairs along vein 4 (bracket) occur on both the dorsal and ventral sides of the wing blade. $|F|$ High-magnification view of $E$, showing ectopic hairs characteristic of the wing margin (bracket).
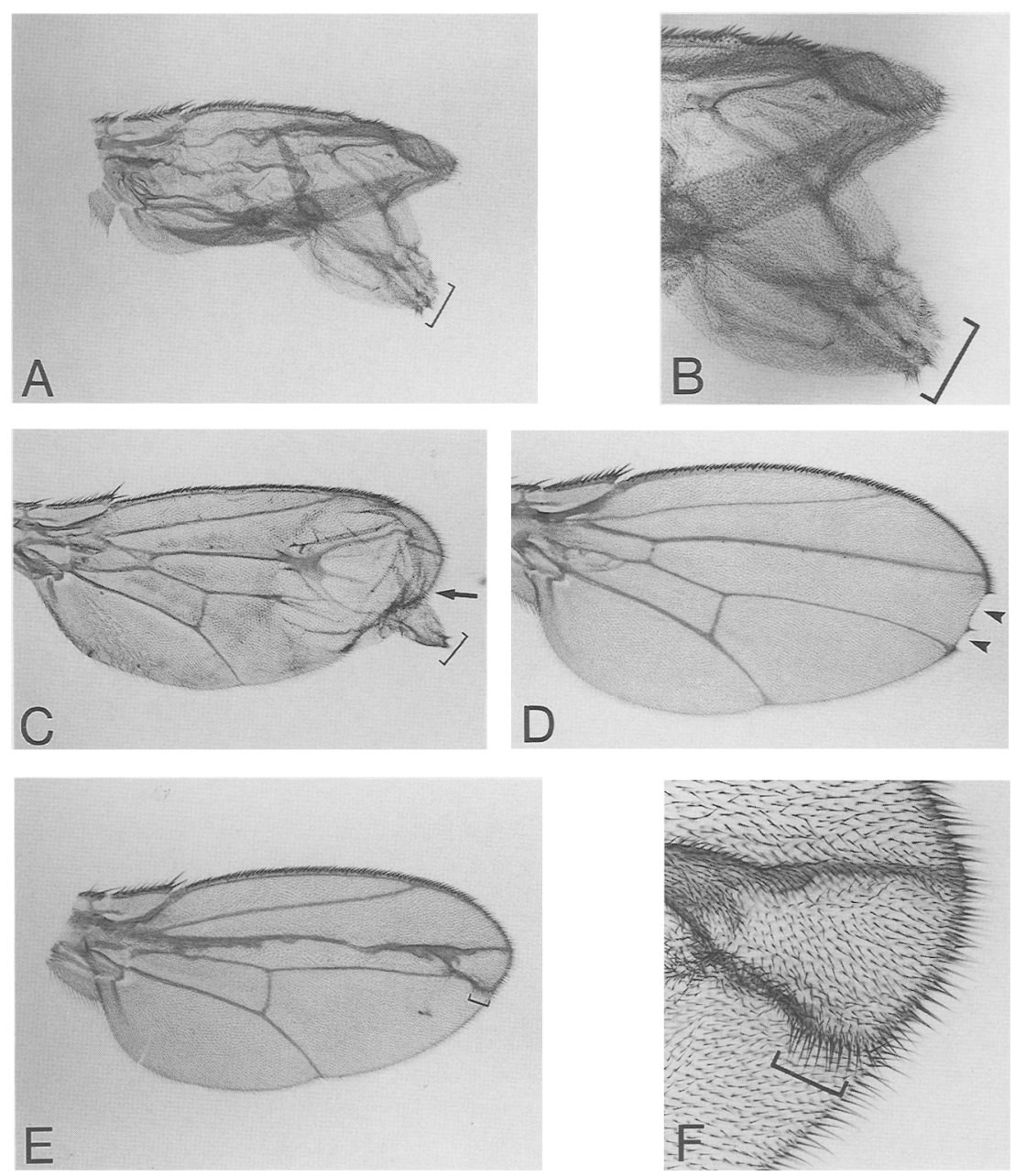

Doherty, in prep.|, only cut and $v g$ have wing phenotypes (for review, see Lindsley and Zimm 1992). There was a notable difference in the ectopic expression of cut, which was induced only in the dorsal compartment of the wing pouch (Fig. 4E; Table 2), whereas $v g$, bib, and $d p n$, like $w g$, wcre induced in both the dorsal and ventral compartments (Fig. 4A-D; data not shown). Furthermore, these discs were distorted by tissue overgrowth in both the dorsal and ventral compartments (cf. Fig. 4A-C with Fig. 2G-I); however, adult wing outgrowth was exclusively dorsal (Fig. 3A-C). Our observations indicate that many genes, including $w g, v g$, and cut, can be downstream targets of $D I$ in the wing disc and that $D I$ has different effects in the dorsal and ventral compartments.

Because ptcG4-DI wing discs displayed such striking outgrowth, we asked whether compartmental organization was disrupted. We examined cxpression of cubitus interuptus, a gene expressed in the anterior compartment, engrailed, a gene expressed in the posterior compartment, and $a p-l a c Z$, an enhancer trap expressed in the dorsal compartment, to determine whether ectopic Dl expression causes general reorganization of the disc. We found that despite the dramatic dorsal and ventral disc tissue outgrowth associated with ectopic Dl expression, both $\mathrm{A} / \mathrm{P}$ and $\mathrm{D} / \mathrm{V}$ compartmental organization appeared undisturbed (data not shown). Our results indicate that $\mathrm{Dl}$ is able to induce many of the aspects of the normal wing margin program including $\mathrm{wg}, \mathrm{vg}$, and cut expression, as well as wing tissue outgrowth and wing margin bristle formation.

\section{Ectopic expression of $\mathrm{N}$ induces wg expression}

We examined ptcG4-N wing discs to determine whether ectopic $\mathrm{N}$ expression induced $w g$ and cut in a manner consistent with its role as a receptor for Dl. Immunohistochemical labeling of ptcG4-N third-instar wing discs with anti- $\mathrm{N}$ and anti-wg antibodies revealed induction of wg expression in a short stripc perpendicular to the $\mathrm{D} / \mathrm{V}$ boundary that gives rise to the wild-type wing margin (white arrowheads in Fig. 4F . ptcG4-N induced $w g$ and cut in many fewer cells than ptcG4-Dl. wg and cut induction occurred in both dorsal and ventral cells but only close to the prospective wing margin (white arrowheads in Fig. 4F,H). Whereas it is formally possible that the levels of $N$ activity were not sufficiently high to induce $w g$ along the entire ptcG4-N stripe, a more likely explanation is that the ectopically expressed $\mathrm{N}$ receptor 

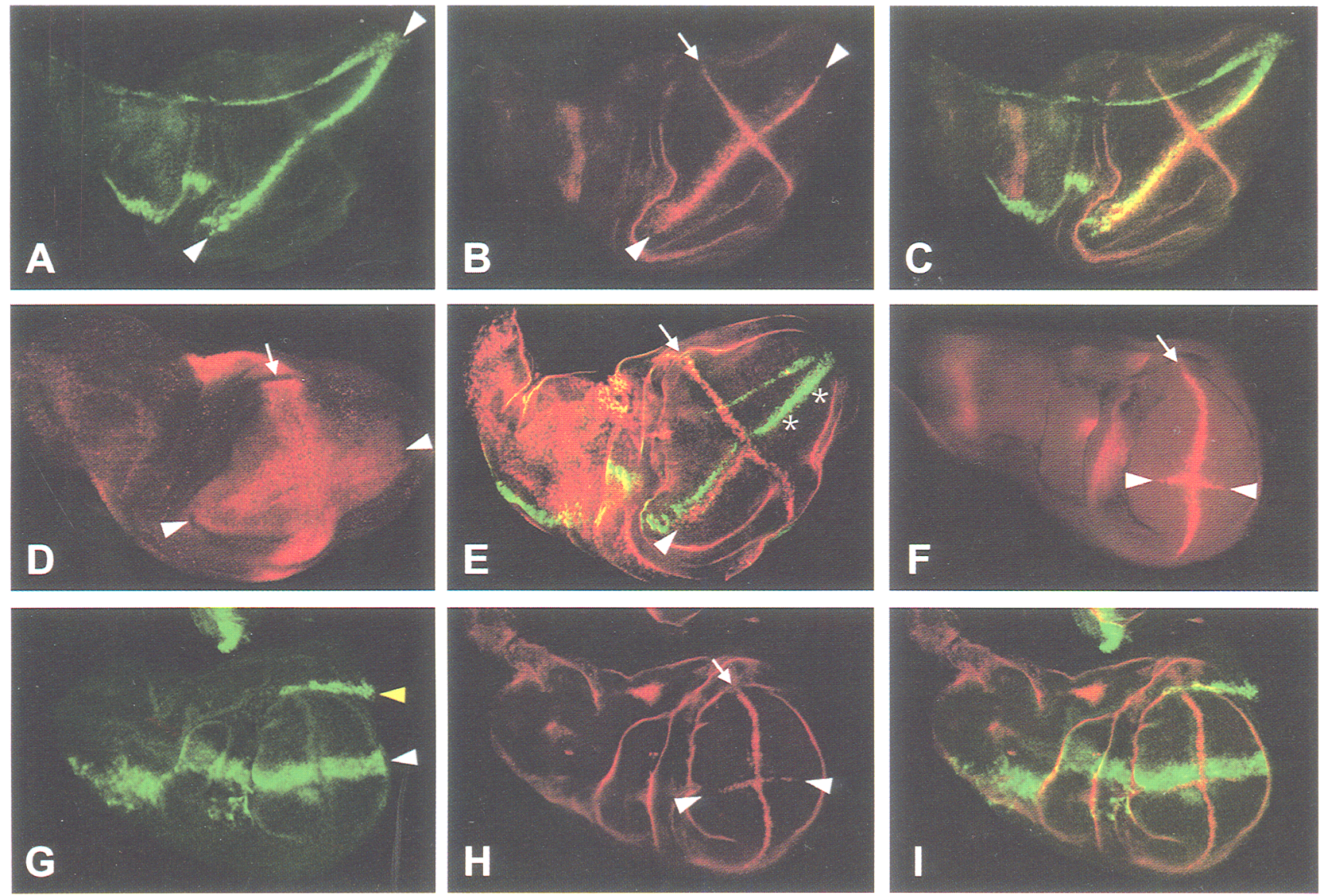

Figure 4. Ectopic D1 or $\mathrm{N}$ expression induces wg, cut, and vg in the third-instar wing disc. Anterior is up and dorsal is left in all images. $(A-E) \mathrm{Dl}, \mathrm{wg}$, vg, and cut expression in a ptcG4-Dl third-instar wing disc. Ectopic $\mathrm{Dl}$ induces wg, vg, and cut expression as well as overgrowth of the dorsal and ventral wing pouch. UAS $-D l$ was expressed using the ptcG4 enhancer trap in larvae raised at $29^{\circ} \mathrm{C}$. (A) Dl (green) is expressed ectopically in a stripe along the $\mathrm{A} / \mathrm{P}$ compartment boundary / white arrowheads|. Endogenous Dl expression is barely visible flanking the $\mathrm{D} / \mathrm{V}$ boundary at this contrast setting. $(B) \mathrm{wg}\langle\mathrm{red}\rangle$ is induced ectopically in a stripe along the $\mathrm{A} / \mathrm{P}$ compartment boundary (white arrowheads). Endogenous wg expression is visible in the $\mathrm{D} / \mathrm{V}$ compartment boundary cells (white arrow). $(C)$ Overlay of $A$ and $B .\{D\}$ vg (red) is induced ectopically in a wide band centered on the A/P compartment boundary (white arrowheads|. Endogenous vg expression is visible in a wide band of cells centered on the D/V boundary (white arrow). (E) cut (red) is induced ectopically in a stripe along the A/P compartment boundary only in the dorsal compartment (white arrowhead). Asterisks ( ${ }^{*}$ ) mark the $\mathrm{A} / \mathrm{P}$ boundary in the ventral compartment that is devoid of cut expression. $(F-I) \mathrm{N}$, wg, and cut expression in a ptcG $4-\mathrm{N}$ third-instar wing disc. Ectopic $N$ induces $w g$ and cut expression. UAS $-N$ was expressed using the ptcG4 enhancer trap in larvae raised at $29^{\circ} \mathrm{C}$. $|F|$ wg $\{$ red $\}$ is induced ectopically in cells along the A/P compartment boundary only near the prospective wing margin $(w h i t e$ arrowheads). Ectopic wg is expressed in cells on both the dorsal and ventral sides of the wing margin. Endogenous wg expression is visible in the wild-type wing margin (white arrow). (G) $\mathrm{N}$ (green) is expressed ectopically in a stripe along the $\mathrm{A} / \mathrm{P}$ compartment boundary (white arrowheads). The yellow arrowhead marks ptcG4-N expression in the peripodial membrane. $(H)$ cut (red) is induced ectopically only in cells along the A/P compartment boundary near the wing margin (white arrowheads). Ectopic cut is expressed in cells on both the dorsal and ventral sides of the wing margin. Endogenous cut expression is visible in the wild-type wing margin in the same cells that express wg (white arrow). (I) Overlay of $G$ and $H$. cut is expressed within the ptcG4-N stripe. There is only a slight overlap (yellow) because $\mathrm{N}$ is a transmembrane protein, whereas cut is nuclear.

was only activated in the cells that are in contact with cells near the wing margin that express $\mathrm{Dl}$ and Ser, known ligands for $\mathrm{N}$ (yellow arrow in Fig. 2G). In other words, endogenous $\mathrm{Dl}$ and/or Ser may activate the ectopically expressed $\mathrm{N}$ in the ptcG4-N stripe, inducing wg and cut expression.

$\mathrm{wg}$ is induced at borders between $\mathrm{Dl}$ expressing and nonexpressing cells

In ptcG4-Dl wing discs, Dl was ectopically expressed at a high level in a stripe several cells wide and endogenous $N$ is expressed throughout the disc; however, $w g$ was not induced throughout the ptcG4-Dl stripe. In the ventral compartment, $w g$ was induced mainly in the cells adjacent to the posterior border of the stripe (Fig. 4A-C), indicating that $D$ l-cxpressing cells do not receive the $\mathrm{Dl}$ signal. In the dorsal compartment, $w g$ was induced in cells along the posterior border of the ptcG4-Dl stripe, in cells outside as well as within the stripe. One explanation for $w g$ induction within the stripe is that $\mathrm{Dl}$ induces 
Table 2. Effects of ectopic DI and Ser expression in the dorsal and ventral compartments

\begin{tabular}{lccc}
\hline & ptcG4-Dl & ptcG4-actN & ptcG4-Scr \\
\hline Dorsal & & & \\
gene expression & & ++ & $-(2)$ \\
wg & ++ & ++ & $-(2)$ \\
$v g$ & ++ & ++ & $-(3)$ \\
$\quad$ cut & ++ & ++ & $-(1)(2)$ \\
disc growth & ++ & N.D. & $-(1)(2)$ \\
adult outgrowth & ++ & N.D. & $-(1)(2)$ \\
wing margin & ++ & & \\
Ventral & & & $++(2)$ \\
gene expression & & ++ & $++(2)$ \\
wg & + & ++ & $++(3)$ \\
vg & ++ & ++ & $++(1)(2)$ \\
$\quad$ cut & - & N.D. & $++(1)(2)$ \\
disc outgrowth & ++ & N.D. & $++(1)(2)$ \\
adult outgrowth & - & & + \\
wing margin & - & & +
\end{tabular}

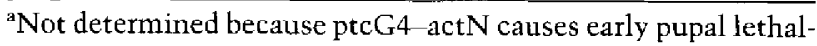
ity.

a(1) Speicher et al. (1994); (2) Kim et al. (1995); (3) D. Doherty and G. Fcger (unpubl).

a reciprocal signal from the cells outside of the stripe /see Discussion|. This reciprocal signal would be capable of inducing $w g$ within the ptcG4-Dl stripe but not cut, as cut was expressed only in cells outside of the stripe /Fig. $4 \mathrm{E}$. Restriction of $w g$ induction to the posterior edge of the ptcG4-Dl stripe cannot be attributable to factors specific to the A/P boundary, because we also observed wg induction at the borders between Dl-expressing and -nonexpressing cells generated by GAL4 lines expressed at other locations.

One possible explanation for these observations is that $\mathrm{Dl}$ autonomously inhibits the ability of a cell to receive Dl signal from other cells. To determine whether increasing the level of $\mathrm{N}$ would allow Dl-expressing cells to receive $\mathrm{Dl}$ signal, we coexpressed $\mathrm{N}$ and $\mathrm{Dl}$ using ptcG4. cut was expressed throughout the width of the ptc 44 stripe in these discs (Fig. $5 \mathrm{~A}-\mathrm{C}$ ), indicating that $\mathrm{N}$ was activated by $\mathrm{Dl}$ throughout the stripe. cut expression was still restricted to the dorsal compartment, as in ptcG4-Dl discs, but it was no longer induced in cells outside the ptc G4 stripc. It is possible that $\mathrm{N}$ expressed within the stripe binds most of the Dl within the stripe, preventing signaling to the adjacent cells that express $\mathbf{N}$ at a lower level. These results provide evidence that $\mathrm{Dl}$ within a cell can inhibit $\mathrm{Dl}$ signal reception by that same cell and that the ratio of $\mathrm{Dl}$ to $\mathrm{N}$ within a cell may determine its ability to both send and receive the $\mathrm{Dl}$ signal.

$\mathrm{Dl}$ and Ser have different signaling abilities in the dorsal and ventral compartments

Dorsal and ventral cells respond differently to ectopic $\mathrm{Dl}$ expression (Table 2). Dl induces higher levels of $w g$ in the dorsal compartment than in the ventral compartment, and cut expression and adult wing outgrowth are restricted to the dorsal compartment. Even when high levels of $\mathrm{Dl}$ and $\mathrm{N}$ are coexpressed in the ventral compartment, cut expression and adult wing outgrowth are not induced in the ventral compartment (Fig. 5A-C; data not shown). Similarly, dorsal and ventral cells respond differently to ectopic Ser expression (Speicher et al. 1994; Kim et al. 1995; Table 2). Ser-induced wg, cut, and vg expression, as well as both disc and adult wing outgrowth, are restricted to the ventral compartment (Kim et al. 1995; Table 2; data not shown). Ser can partially substitute for $\mathrm{Dl}$ during neurogenesis in the embryo $/ \mathrm{Gu}$ et al. 1995), and Dl and Ser have been shown to bind the same EGF repeat in N (Rebay et al. 1991); thus the Dlinduced $w g$ and $v g$ expression in the ventral compartment may indicate that $\mathrm{Dl}$ can partially substitute for Ser. Nonetheless, ectopically expressed Dl and Ser have strikingly different effects in the dorsal and ventral compartments.

Is the specificity attributable to compartmental differences in receptor-ligand interactions, or is it attributable to compartmental differences in the downstream response of the $\mathrm{N}$ pathway? To answer this question, we expressed a constitutively active truncated $\mathrm{N}$ protein (actN) using ptcG4. At $16^{\circ} \mathrm{C}$, ptcG4-actN animals die as early pupae; however, third-instar wing discs displayed extreme outgrowth in both dorsal and ventral compartments, and cut was induced equally in the dorsal and ventral compartments (Fig. 5D-F). This result indicates that the factors responsible for compartment-specific $\mathrm{N}$ signaling act on or upstream of the $\mathrm{N}$ receptor.

\section{Discussion}

We have shown that $D I$ is required during Drosophila wing development as a ventral to dorsal signal. Mitotic clones lacking $D I$ that include cells on the ventral side of the $\mathrm{D} / \mathrm{V}$ boundary cause loss of wing margin and blade tissuc in both compartments, and Dl protein is elevated at the $\mathrm{D} / \mathrm{V}$ compartment boundary of second-instar larval wing discs. Furthermore, ectopic Dl expression induces wing margin formation and wing tissue outgrowth. In light of these findings, we discuss the role of other genes in the $N$ signaling pathway, the likely involvement of A/P boundary signaling components, and the requirement for a border between signaling and receiving cells at the $\mathrm{D} / \mathrm{V}$ boundary during normal wing development. We also propose a model for $D I$ and Ser function during the early steps of wing margin formation in the second-instar wing disc.

\section{The $\mathrm{Dl}-\mathrm{N}$ signaling pathway is required for wing formation}

The $D I-N$ pathway consists of a cassette of genes that functions to transmit signals between cells at many stages during development (Jan and Jan 1993; ArtavanisTsakonas et al. 1995), and we have shown that Dl plays an essential role in wing development, probably by acti- 

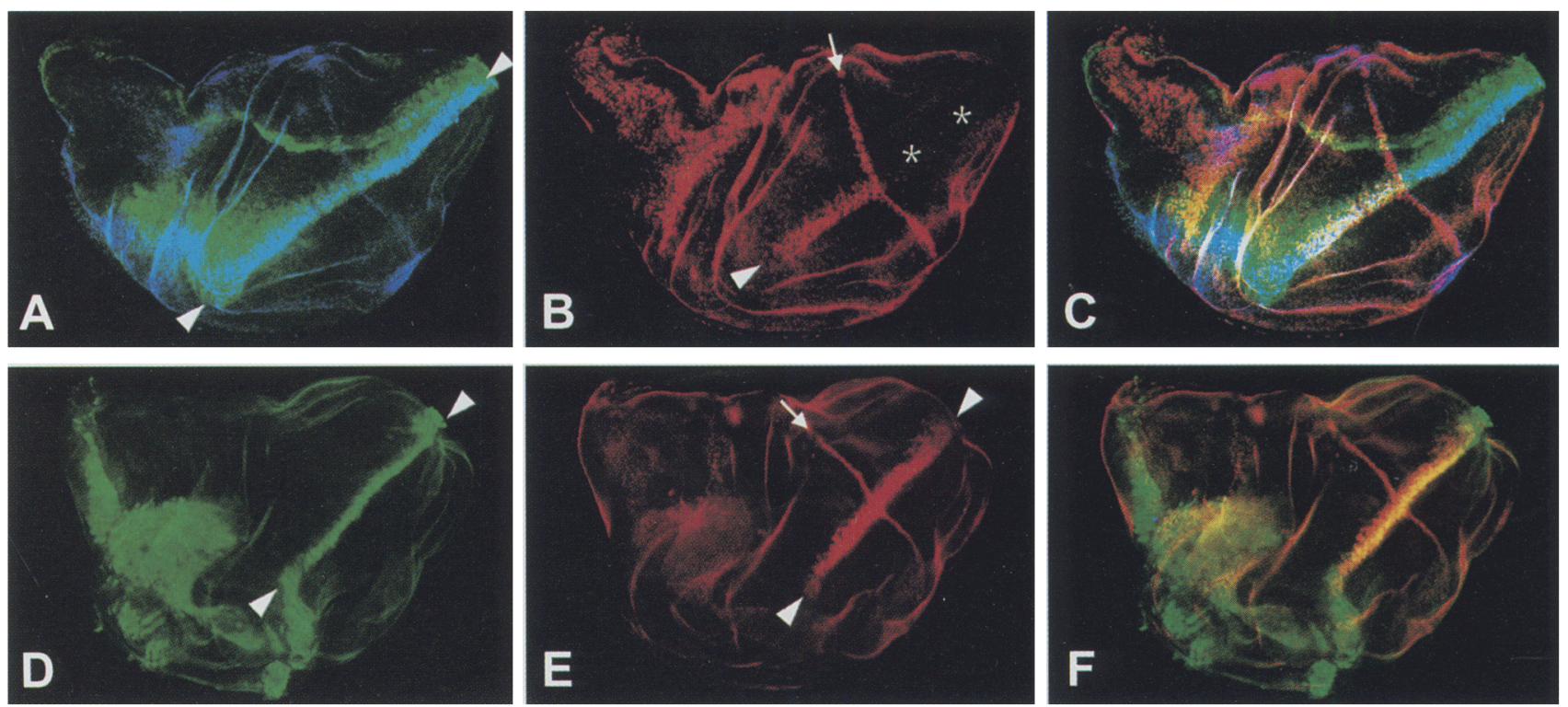

Figure 5. cut expression in ptcG4-Dl $+\mathrm{N}$ and ptcG4-activated $\mathrm{N}$ third-instar wing discs. $(A-C) \mathrm{Dl}, \mathrm{N}$, and cut expression in a ptcG4-Dl $+\mathrm{N}$ third-instar disc. Ectopic $\mathrm{N}$ and $\mathrm{Dl}$ together still induce cut expression only in the ventral compartment. UAS-DI and UAS $-N$ were expressed using the ptcG4 enhancer trap in larvae raised at $29^{\circ} \mathrm{C}$. $\{A \mid \mathrm{Dl}$ (blue) and $\mathrm{N}$ (green) are expressed ectopically in a stripe along the $\mathrm{A} / \mathrm{P}$ compartment boundary (white arrowheads). (B) cut (red) is induced ectopically within the ptcG4 stripe only in the dorsal compartment (white arrowhead). Asterisks ( ${ }^{*}$ ) mark the A/P boundary in the ventral compartment that is devoid of cut expression. $(C)$ Overlay of $A$ and $B$. Ectopic $\mathrm{Dl}, \mathrm{N}$, and cut expression overlap in the dorsal compartment (white signal) but not in the ventral compartment (blue signal). $(D-F) \mathrm{N}$ and cut expression in a ptcG4-activated $\mathrm{N}$ third-instar disc. Ectopic-activated $\mathrm{N}$ induces cut expression in the dorsal and ventral compartments. UAS-activated $N$ was expressed using the ptcG 4 enhancer trap in larvae raised at $16^{\circ} \mathrm{C} .(D)$ activated $\mathrm{N}$ (green) is expressed ectopically in a stripe along the A/P compartment boundary (white arrowheads $\mid$. $(E)$ cut (red) is induced ectopically within the ptcG4 stripe in both the dorsal and ventral compartments (white arrowheads). Endogenous cut expression is visible at the D/V boundary (white arrow). $(F)$ Overlay of $D$ and $E$. Ectopic-activated $\mathrm{N}$ and cut expression overlap in the dorsal and ventral compartments.

vating $\mathrm{N}$. We propose that in addition to $N, D l$, and Ser, other genes in the cassette are likely to be involved in wing development. Suppressor of Hairless $[\mathrm{Su}(H)]$ is downstream of $N$ in the signaling pathway, and $\mathrm{Su}(\mathrm{H})$ protein has been shown to translocate from the cytoplasm to the nuclcus upon activation of $\mathrm{N}$ by $\mathrm{Dl}$ in transfected S2 cells (Fortini and Artavanis-Tsakonas 1994). Consistent with the requirement for $N$ in wing margin formation and growth, decreased $\mathrm{Su}(H)$ function results in a small third-instar wing pouch (Schweisguth and Posakony 1992) and very small adult wings, reminiscent of $\mathrm{Vg}$ mutant wings (Ashburner 1982). Su(H) activity is antagonized by Hairless $[H]$, which encodes a novel nuclcar protein (Bang and Posakony 1992). Loss of $H$ function leads to the opposite phenotype, an abnormally large wing pouch (Bang et al. 1991). Thus, it appears that multiple elements of the $D l-N$ signaling pathway operate during wing margin formation.

$w_{g} g$ has been shown to interact with $N$ during wing margin formation, indicating that these two genes function in the same pathway (Couso and Martinez-Arias 1994; Hing et al. 1994). Couso and Martinez-Arias (1994) proposed several molecular models to explain this interaction, favoring a model in which $\mathrm{N}$ functions as a receptor for wg. The observations that $N$ is required for $w g$ expression (Rulifson and Blair 1995) and that ectopic N and $\mathrm{Dl}$ induce wg demonstrate that wg is a downstream target of the $D I-N$ signaling pathway; however, we cannot eliminate the possibility that wg also functions upstream of $N$ earlier during wing development.

\section{Adult wing outgrowth requires factors expressed at the A/P compartment boundary}

Our ectopic Dl expression experiments indicate that $D I$ can be sufficient to induce wing margin formation. We have strong evidence that the effects of ectopic $\mathrm{Dl}$ expression reflect the function of $D 1$ during wild-type development. The UAS $-D l$ construct produces protein that is localized to the plasma membrane and cytoplasmic vesicles in a manner indistinguishable from wild-type $\mathrm{Dl}$, and UAS-Dl rescues the $\mathrm{Dl}$ loss-of-function neurogenic phenotype in the embryo when driven by hairy-G4 (see Materials and methods). Furthermore, the ectopic expression phenotype is opposite to the loss-of-function phenotype and requires normal activity of $\mathrm{N}$, the only known receptor for $\mathrm{Dl}$.

We have found that ectopic expression of $\mathrm{Dl}$ near the A/ $P$ compartment boundary results in adult wing tissue outgrowth. Ectopic expression at other locations in the wing pouch causes ectopic gene expression and outgrowth of wing disc tissue but not adult wing tissue out- 
growth. Dl-induced adult outgrowth is always associated with wing margin structures, indicating that disc tissue overgrowth may resolve unless it is maintained by an established wing margin. Distal outgrowth caused by fng ${ }^{-}$clones also occurs only near the A/P boundary (Irvine and Wieschaus 1994). It is therefore likely that factors specific to the $\mathrm{A} / \mathrm{P}$ border are required for induction of an ectopic wing margin and the resulting wing outgrowth. One candidate is decapentaplegic $\{d p p\}$ that is expressed along the A/P border (Posakony et al. 1990). Ectopic $d p p$ expression induces growth and pattern duplication in the wing (Capdevila et al. 1994). Moreover, overlapping expression of $w g$ and $d p p$ in the leg disc is required for proximodistal growth (Struhl and Basler 1993|. Ectopic Dl-induced growth cannot be simply due to the ectopic expression of $w g$ in $d p p$-expressing cells along the $\mathrm{A} / \mathrm{P}$ boundary, because neither Dl-induced $w g$ expression in the ventral compartment nor ptcG4-driven $w g$ expression in both compartments is sufficient to cause adult wing outgrowth Fig. 3A; E. Wilder, pers. comm.). It appears that the constellation of ectopic gene expression induced by ptcG4-Dl acts in concert with endogenous factors at the $\mathrm{A} / \mathrm{P}$ compartment boundary to cause ectopic wing outgrowth. It will be interesting to determine how endogenous factors at the $\mathrm{D} / \mathrm{V}$ and $\mathrm{A} / \mathrm{P}$ boundaries interact to cause growth of the wing.

\section{DI can inhibit signal reception by $N$ in the same cell}

Ectopic Dl expression induces wg and cut only at the borders between Dl-expressing and -nonexpressing cells and not in all cells that express ectopic Dl. One possible explanation for this observation is that $\mathrm{Dl}$ inhibits $\mathrm{N}$ receptor activity when expressed within the same cell as $\mathrm{N}$; Irvine and Wieschaus (1994) have proposed an analogous model for fing and its putative receptor. In our model, the ratio of $\mathrm{Dl}$ to $\mathrm{N}$ within a cell would determine its ability to receive a signal via N. Signaling would only occur when cells with a Dl/ $\mathrm{N}$ ratio low enough to allow signal reception are juxtaposed to Dl-expressing cells. This model explains why there is decreased Dl signaling within the ptcG4-Dl stripe. We have tested three predictions of this model: (1) Signaling should be strongest between cells that express high levels of $\mathrm{Dl}$ and cells that express low levels of DI. We observe maximal wg and cut induction immediately posterior to the ptcG4$\mathrm{Dl}$ stripe, where cells expressing high $\mathrm{Dl}$ levels are juxtaposed to cells expressing low levels. (2) Increasing the level of $\mathrm{N}$ should relieve the Dl-mediated inhibition of $\mathrm{N}$ receptor activity. As expected, in discs expressing $\mathrm{N}$ and $\mathrm{Dl}$ under the control of ptcB4, cut is expressed throughout the width of the ptcG4 stripe. (3) Expressing high levels of $\mathrm{Dl}$ should mimic reduction in $N$ function. This prediction is met by two paradoxical observations. D1 overexpression in the wing blade results in hypertrophy of wing veins (Fig. 3A-C), and Dl overexpression in the proneural cluster results in the development of extra sense organs; both of these phenotypes are similar to those caused by reduction in $N$ or $D l$ activity (Parks and
Muskavitch 1993; de Celis and Garcia-Bellido 1994; Fig. 1C-F; D. Doherty and G. Feger, unpubl.).

Dl could exert its inhibitory effect on $\mathrm{N}$ activity by directly interacting with $\mathrm{N}$ or by indirectly inhibiting $\mathrm{N}$ activity via other proteins. Alternatively, Fehon et al. (1990) proposed that $\mathrm{Dl}$ in receiving cells might interfere with $\mathrm{N}$ signaling by binding $\mathrm{Dl}$ ligand on the signaling cells. It should be noted that inhibition of signal reception by Dl does not appear to play a role in the early D/V patterning of the wing, because we did not detect a sharp border between $D l$-expressing and -nonexpressing cells; however, later, the wg stripe is flanked on both sides by $\mathrm{Dl}$-expressing cells, and signaling from $\mathrm{Dl}$-expressing to -nonexpressing cells may be important.

\section{A model for symmetrical gene activation at the $D / V$ boundary}

$N$ activity is required on both sides of the $\mathrm{D} / \mathrm{V}$ boundary for wing margin formation, whereas $D I$ and Ser are each required only on the ventral and dorsal sides, respectively. In addition, cells in the dorsal and ventral compartments respond differently to ectopically expressed Ser and $\mathrm{Dl}$, whereas cells in both compartments respond equally to ectopically expressed activated $\mathrm{N}$ (Table 2). One possible explanation for the different activities of $D 1$ and Ser could be their roles as compartment-specific signals. Bidirectional signaling between dorsal and ventral compartment cells has been invoked as a mechanism to generate the wing margin and symmetric growth of the wing (Irvine and Wieschaus 1994; Williams et al. 1994; Rulifson and Blair 1995|. Compartment-specific signaling can be generated by spatial restriction of the ligand or by spatial restriction of the response. For example, fng and Ser are expressed only in the dorsal compartment of second-instar wing discs (Irvine and Wieschaus 1994; cited in Kim et al. 1995|. Furthermore, Ser is ectopically induced at the borders of $\mathrm{ng}^{-}$clones in the dorsal compartment, and ectopic fng induces Ser in the ventral compartment; however, ectopic Ser does not induce fng, indicating that $S e r$ functions downstream of fng. Irvine and Wieschaus (1994) have proposed that fng encodes a compartment-specific dorsal to ventral signal, and Kim et al. \{1995| have shown that fng-expressing dorsal cells can recognize when they are adjacent to cells not expressing fing and respond by activating expression of Ser, which they propose encodes a dorsal to ventral signal. The existence of a reciprocal signal from ventral to dorsal cells is based on the observation that cells both inside and outside fng $^{-}$or $a p^{-}$clones are transformed into wing margin (Irvine and Wieschaus 1994; Williams et al. 1994). The $\mathrm{N}$ receptor is required for signaling in both directions, because loss of $N$ function on one side of the $\mathrm{D} / \mathrm{V}$ boundary eliminates $\mathrm{wg}$ expression and causes loss of wing tissue on both sides of the boundary (de Celis and Garcia-Bellido 1994; Rulifson and Blair 1995).

We propose that $\mathrm{Dl}$ acts as a ventral to dorsal signal that activates $\mathrm{N}$ to induce wing margin-specific genes during second-instar development. Dl displays three characteristics expected of such a signal: (1) $D l$ is re- 
quired in ventral cells at the $\mathrm{D} / \mathrm{V}$ boundary for wing margin formation; (2) $\mathrm{Dl}$ is expressed at the $\mathrm{D} / \mathrm{V}$ compartment boundary in second-instar discs; (3) ectopic D1 can induce ectopic wing margin formation and wing outgrowth, but only in the dorsal compartment. For the Dl signal, restriction of the response plays an important role in compartment specificity. For Ser, restriction of the response as well as restriction of the ligand is important, because Ser is expressed only in the dorsal compartment, and only ventral cells respond to ectopic Ser.

We propose the following model to explain the early steps of wing margin formation during the second larval instar |Fig. 6|. Ser in the dorsal compartment induces $w g$ expression and $D 1$ expression or activity in ventral compartment cells. In turn, $\mathrm{Dl}$ in ventral compartment cells signals back to dorsal compartment cells via $N$ to induce wg and to reinforce Ser expression or activity (Fig. 6). Preliminary results indicate that ectopic Dl expression induces Ser in the dorsal compartment of ptcG4-Dl discs (C. Micchelli, pers. comm.) and that ectopic Ser induces $D I$ in the ventral compartment of ptcG4-Ser discs (D. Doherty and G. Feger, unpubl.). Kim et al. (1995) have shown that fng acts upstream of Ser to activate Ser expression. The role of fng could be to initiate the positive feedback loop between DI and Ser either by signaling from dorsal to ventral cells to activate $D 1$ in the ventral cells, or by inhibiting the response to Ser and activating the response to $D l$ in dorsal cells creating a border for $D I$ and Ser signaling, or both. As wing development proceeds, the early pattern of $D l$ expression evolves into the third-instar pattern where $D l$ is expressed in two stripes flanking the $w g$-expressing cells at the $\mathrm{D} / \mathrm{V}$ boundary. It is likely that the combined activities of $\mathrm{wg}, \mathrm{Dl}$, Ser, and other genes generate the later expression pattern. This

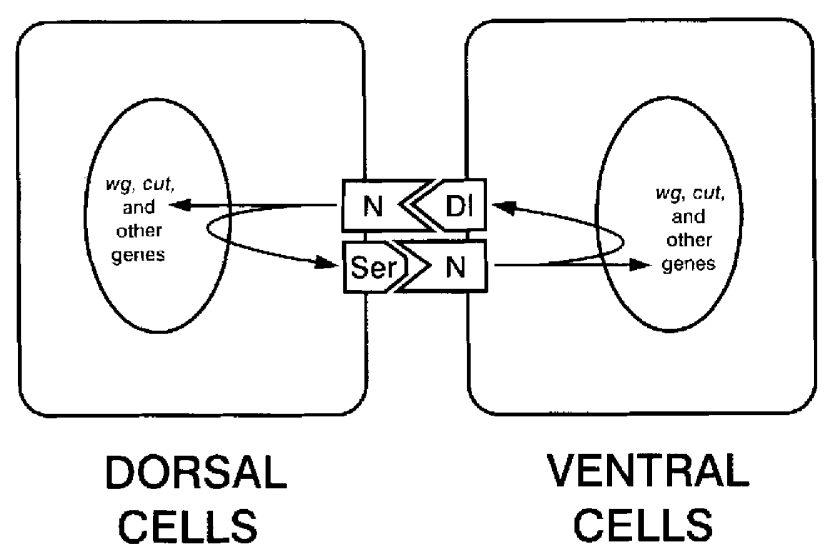

Figure 6. Model for symmetrical gene expression at the $D / V$ boundary mediated by a positive feedback loop. Dl signals from ventral to dorsal cells via $\mathrm{N}$ to activate or maintain Ser and wg expression, whereas Ser signals from dorsal to ventral cells via $\mathrm{N}$ to activate or maintain $D I$ and wg expression. As wing development proceeds, the early pattern of $D I$ and Ser expression evolves into the third-instar pattern where $D l$ and Ser are expressed in two stripes flanking the wg-expressing cells at the $\mathrm{D} / \mathrm{V}$ boundary. It is likely that the combined activities of $\mathrm{wg}$, Dl, Ser, and other genes generate this later expression pattern. system enables an intrinsically asymmetric boundary between ap-expressing and -nonexpressing cells to induce the symmetric patterns of growth and gene expression required to form the wing.

\section{Conservation of mechanisms for axis formation and distal outgrowth in appendage development}

How axes are specified is a universal problem during appendage development. Data from a variety of species suggest that there may be a limited number of molecular mechanisms for generating axes and other pattern information. For example, the hedgehog pathway is used to pattern different types of appendages in animals as evolutionarily divergent as the fly, chicken, and mouse (for review, see Perrimon 1995; Tabin 1995). The DI-N signaling pathway described in this paper may also be used in vertebrate limbs. Jagged, a murine member of the DII Ser family, is expressed in developing limbs (Lindsell et al. 1995!. Wnt-7a, a mouse homolog of wg, has been shown to function in D/V patterning of limbs (Parr and McMahon 1995; Riddle et al. 1995). It remains to be determined whether the $D 1-N / S e r-N$ signaling pathways are used for limb axis formation throughout the animal kingdom.

\section{Materials and methods}

Clonal analysis

Adult mosaic clones of mutant $D I$ tissue were generated by $\mathrm{X}$-irradiating second-instar larvae, as described by Diaz-Benjumea and Cohen (1993). To mark the $\mathrm{Dl}^{+}$chromosome, we used a forked ${ }^{+}$duplication on the third chromosome (distal to $D l$ at cytological map position 98B), kindly provided by F. DiazBenjumea and S. Cohen, European Molecular Biology Laboratory (EMBL), Heidelberg, Germany. This allowed us to identify Dl forked clones in flies hemizygous for $f^{36 a}$. We used $D T^{\text {rev10 }}$, a loss-of-function DI allele (Heitzler and Simpson 1991), which gave no detectable $\mathrm{Dl}$ protein in homozygous $D P^{\text {revio }}$ embryos.

For analysis in wing discs, mitotic clones lacking $D l$ were generated using flipase-mediated mitotic recombination (Golic and Lindquist 1989; Golic 1991). We recombined $D I^{\text {revto }}$ and ebony, a recessive mutation that darkens cuticular structures, onto a chromosome carrying $\mathrm{p}\left[\mathrm{FRT}\right.$, neo, $r \mathrm{y}^{+}$] at $82 \mathrm{~B}$ [Xu and Rubin 1993). We crossed this chromosome into flies with a heat shock Myc-marked p[FRT, neo, ry $\left.{ }^{+}\right]$third chromosome and a heat shock flipase $\mathrm{X}$ chromosome and generated homozygous clones in wing discs and adult wings (see Xu and Rubin 1993). We identified DJ mutant clones by the absence of Myc expression in wing disc cells. Many wing discs with clones induced during second instar were extremely distorted, making them difficult to analyze.

\section{Immunocytochemistry}

Larvae were dissected in phosphate-buffered saline (PBS), fixed for $10 \mathrm{~min}$ in $4 \%$ formaldehyde and PEMS $10.1 \mathrm{M}$ PIPES at $\mathrm{pH}$ 6.9, 1 mM EGTA, $2 \mathrm{mM} \mathrm{MgSO}_{4}$ l, rinsed several times in PBT, blocked for $1 \mathrm{hr}$ at room temperature with $2 \%$ normal goat serum, and incubated overnight at $4^{\circ} \mathrm{C}$ with the primary antibody. After several washes with PBT, fluorescent-labeled secondary antibodies (Jackson Laboratories, USA) were added for 1-2 hr at room temperature, washed with PBT, and mounted in 
glycerol/PBS/2\% n-propylgallate. Samples were examined using a Bio-Rad MRC-600 confocal microscope. The following antibodies were used: rabbit anti- $\beta$-galactosidase (Cappel, USA) mouse anti-Dl mAb 202 (Kooh et al. 1993), rabbit anti-Vg (Williams et al. 1991), rat anti-cut (Blochlinger et al. 1988), rabbit anti-N (E. Giniger and Y.N. Jan, in prep.), rabbit anti-wg |van den Heuvel et al. 1989), mouse anti-en (Patel et al. 1989), rabbit anti-cubitus-interuptus (Schwartz et al. 1996), guinea pig antimyc (G. Feger and Y.N. Jan, unpubl.). Confocal figures were assembled using Photoshop 3.0 (Adobe, USA) and Canvas 3.5.3 (Deneba, USA).

\section{Ectopic expression of $\mathrm{N}$ and $\mathrm{Dl}$}

Targeted ectopic expression of $N$ and $D l$ was accomplished using the GAL4 system (Brand and Perrimon 1993). UAS-DI transgenic lines were generated by subcloning $D$ l cDNA 3.2 (Vaessin et al. 1987) into the pUAST vector and transformation into $\mathrm{W}^{-}$ flies by standard techniques. UAS-activated $N$ lines were generated by subcloning the transmembrane and intracellular domain sequences of $N$ fused to the $D I$ signal sequence into pUAST (E. Giniger, pers. comm.). To test for wild-type function of the UAS-Dl constructs we used hairy-GAL4-driven expression of UAS-Dl to rescue the neurogenic phenotype of $D l^{9 P 39}$ mutant embryos (D. Doherty and Y.N. Jan, in prep.). The UASactivated $N$ constructs displayed antineurogenic activity in embryos when expressed with hairy-GAL4, as expected for a constitutively active $N$ construct (Lieber et al. 1993; Rebay et al. 1993; Struhl et al. 1993).

UAS-Dl, UAS-activated $N$, and UAS- $N$ /gift from L. Seugnet, M. Haenlin, and P. Simpson, CNRS, Strasbourg, Francel ectopic expression in imaginal discs was targeted using ptc GAL4 (Hinz et al. 1994) and other GAL4 enhancer trap lines. Homozygous GAL4 flies were crossed to UAS-D1/TM $6 B$, Tb, or homozygous UAS $-N$ flies and grown at either $18^{\circ} \mathrm{C}, 22^{\circ} \mathrm{C}$, or $29^{\circ} \mathrm{C}$, as indicated. Larvae carrying both the GAL4 and the UAS insertions were identified on the basis of the $\mathrm{Tb}^{+}$phenotype.

The expression pattern of ptcGAL4 was examined by crossing it to a UAS-lacZ reporter line carrying a nuclear localized $\beta$-galactosidase under UAS control.

\section{Genetics and temperature shifts}

To test for $N^{\text {ts }}$ suppression of the ptcG4-Dl adult phenotype, we crossed $w, N^{t s} / F M 6$; ptc GAL4 females to y $w$; UAS-D1/TM $6 B$, $T b$ males in vials. We collected eggs in vials over a period of 24 hr (at $22^{\circ} \mathrm{Cl}$, incubated the vials at $22^{\circ} \mathrm{C}$ until the larvae had developed to second instar, and then shifted the vials to $29^{\circ} \mathrm{C}$ for $24 \mathrm{hr}$. A range of abnormal wing outgrowth phenotypes was observed in both classes $\left(y w / N^{t s}\right.$ and $\left.y w / F M G\right)$ of ptc-Dl females, whereas none of the $w N^{t s} / Y$; ptc-Dl males had abnormal wing outgrowth.

All flies were grown on standard cornmeal-agar medium at room temperature unless otherwise noted. Mutations not specifically discussed here are described in Lindsley and Zimm (1992).

\section{Acknowledgments}

We thank S. Barbel and L. Ackerman for artwork, C. Bargmann, P. Kolodziej, and I. Clark for helpful comments on the manuscript, and S. Ralls for technical help with the GAL4 screen and the UAS nuclear lacZ construct. We thank J. Kim for helpful comments and for sharing his manuscript prior to publication. We are par- ticularly indebted to E. Rulifson, C. Micchelli, and S Blair for sharing results prior to publication, for helpful discussions, and for valuable comments on the manuscript. We would also like to thank T. Parody and M.A.T. Muskavitch for $\mathrm{Dl}$ antibodies, R. Nusse for wg antibody, J. Gates and S.B. Carroll for vg antibody, C. Schwartz and T. Kornberg for en and ci antibody, E. Giniger for UAS D1 UAS-act $N$, and N antibody, L. Seugnet, M. Haenlin, and $\mathrm{P}$. Simpson for making UAS- $N$ available prior to publication as well as for $D l^{\text {revio }}, \mathrm{B}$. Wilder for sharing results prior to publication, and F. Diaz-Benjumea and S. Cohen for the bld $\mathrm{cu} f^{+98 B}$ chromosome and sharing their manuscript prior to publication. This work was supported by the Howard Hughes Medical Institute. L.Y.J. and Y.N.J. are Howard Hughes investigators.

The publication costs of this article were defrayed in part by payment of page charges. This article must therefore be hereby marked "advertisement" in accordance with 18 USC section 1734 solely to indicate this fact.

\section{References}

Artavanis-Tsakonas, S., K. Matsuno, and M.E. Fortini. 1995. Notch signaling. Science 268: 225-232.

Ashburner, M. 1982. The genetics of a small autosomal region of Drosophila melanogaster containing the structural gene for alcohol dehydrogenase. III: Hypomorphic and hypermorphic mutations affecting the expression of Hairless. Genetics 101: 447-459.

Baker, N.E. 1988. Transcription of the segment polarity gene wingless in the imaginal discs of Drosophila, and the phenotype of a pupal-lethal wg mutant. Development 102: 489497.

Bang, A.G. and J.W. Posakony. 1992. The Drosophila gene Hairless encodes a novel basic protein that controls cell fates in adult sensory organ development. Genes \& Dev. 6: 17521769 .

Bang, A.G., V. Hartenstein, and J.W. Posakony. 1991. Hairless is required for the development of adult sensory organ precursor cells in Drosophila. Development 111: 89-104.

Bier, E., H. Vaessin, S. Younger-Shepherd, L.Y. Jan, and Y.N. Jan. 1992. deadpan, an essential pan-neural gene in Drosophila, encodes a helix-loop-helix protein similar to the hairy gene product. Genes \& Dev. 6: $2137-2151$.

Blair, S.S. 1993. Mechanisms of compartment formation: Evidence that non-proliferating cells do not play a critical role in defining the $\mathrm{D} / \mathrm{V}$ lineage restriction in the developing wing of Drosophila. Development : 339-351.

- 1995. Compartments and appendage development in Drosophila. BioEssays 17: 299-309.

Blochlinger, K., R. Bodmer, J. Jack, L.Y. Jan, and Y.N. Jan. 1988. Primary structure and expression of a product from cut, a locus involved in specifying sensory organ identity in Drosophila. Nature 333: 629-635.

Blochlinger, K., L.Y. Jan, and Y.N. Jan. 1993. Postembryonic patterns of expression of cut, a locus regulating sensory organ identity in Drosophila. Development 117: 441-450.

Bourgouin, C., S.E. Lundgren, and J.B. Thomas. 1992. apterous is a Drosophila LIM domain gene required for a subset of embryonic muscles. Neuron 9: 549-561.

Brand, A.H. and N. Perrimon. 1993. Targeted gene expression as a means of altering cell fates and generating dominant phenotypes. Development 118: 401-415. 
Bryant, P.J. 1975. Pattern formation in the imaginal wing disc of Drosophila melanogaster: Fate map, regeneration and duplication. I. Exp. Zool. 193: 49-77.

Campos-Ortega, J.A. 1988. Cellular interactions during early neurogenesis of Drosophila melanogaster. Trends Neurosci. 11: $400-405$.

Capdevila, J., M.P. Estrada, E. Sanchez-Herrero, and I. Guerrero. 1994. The Drosophila segment polarity gene patched interacts with decapentaplegic in wing development. EMBO I. 13: $71-82$.

Couso, J.P. and A. Martinez-Arias. 1994. Notch is required for wingless signaling in the epidermis of Drosophila. Cell 79: $259-272$.

Couso, J.P., M. Bate, and A. Martinez-Arias. 1993. A winglessdependent polar coordinatc system in Drosophila imaginal discs. Science 259: 484-489.

de Celis, J.F., and A. Garcia-Bellido. 1994. Roles of the Notch gene in Drosophila wing morphogenesis. Mech. Dev. 46: $109-122$.

Diaz-Benjumea, F.J. and S.M. Cohen. 1993. Interaction between dorsal and ventral cells in the imaginal disc directs wing development in Drosophila. Cell 75: 741-752.

- 1995. Serrate signals through Notch to establish a Wingless-dependent organizer at the dorsal/ventral boundary of the Drosophila wing. Development 121: 4215-4225.

Fehon, R.G., P.J. Kooh, I. Rebay, C.L. Regan, T. Xu, M.A.T. Muskavitch, and S. Artavanis-Tsakonas. 1990. Molecular interactions between the protein products of the neurogenic loci Notch and Delta, two EGF-homologous genes in Drosophila. Cell 61: 523-534.

Fleming, R.J., T.N. Scottgale, R.J. Dicderich, and S. ArtavanisTsakonas. 1990. The gene Serrate encodes a putative EGFlike transmembrane protein essential for proper ectodermal development in Drosophila melanogaster. Genes \& Dev. 4: $2188-2201$.

Fortini, M.E. and S. Artavanis-Tsakonas. 1994. The Suppressor of Hairless protein participates in Notch receptor signaling. Cell 79: 273-282.

French, V., P.J. Bryant, and S.V. Bryant. 1976. Pattern regulation in epimorphic fields. Science 193: 969-981.

Garcia-Bellido, A., P. Ripoll, and G. Morata. 1973. Developmental compartmentalisation of the wing disk of Drosophila. Nature 245: 251-253.

Ghysen, A., C. Dambly-Chaudière, L.Y. Jan, and Y.N. Jan. 1993. Cell interactions and gene interactions in peripheral neurogenesis. Genes \& Dev. 7: 723-733.

Golic, K.G. 1991. Site-specific recombination between homologous chromosomes in Drosophila. Science 252: 958-961.

Golic, K.G. and S. Lindquist. 1989. The FLP recombinase of yeast catalyzes site-specific recombination in the Drosophila genome. Cell 59: 499-509.

Gu, Y., N.A. Hukriede, and R.J. Fleming. 1995. Serrate expression can functionally replace Delta activity during neuroblast segregation in the Drosophila embryo. Development 121: $855-865$.

Heitzler, P. and P. Simpson. 1991. The choice of cell fate in the epidermis of Drosophila. Cell 64: 1083-1092.

Hing, H.K., X. Sun, and S. Artavanis-Tsakonas. 1994. Modulation of wingless signaling by Notch in Drosophila. Mech. Dev, 47: 261-268.

Hinz, U., B. Giebel, and J.A. Campos-Ortega. 1994. The basichelix-loop-helix domain of Drosophila lethal of scute protein is sufficient for proneural function and activates neurogenic genes. Cell 76: 77-87.

Irvine, K.D. and $\mathrm{E}$. Wieschaus. 1994. fringe, a boundary-specific signaling molecule, mediates interactions between dorsal and ventral cells during Drosophila wing development. Cell 79: $595-606$

Jan, Y.N. and L.Y. Jan. 1993. Functional gene cassettes in development. Proc. Natl. Acad. Sci. 90: 8305-8307.

Kim, J., K.D. Irvine, and S.B. Carroll. 1995. Cell recognition, signal induction, and symmetrical gene activation at the dorsal/ventral boundary of the developing Drosophila wing. Cell 82: 795-802.

Klingensmith, I. and R. Nusse. 1994. Signaling by wingless in Drosophila. Dev. Biol. 166: 396-414.

Kooh, P.I., R.G. Fehon, and M.A.T. Muskavitch. 1993. Implications of dynamic patterns of Delta and Notch expression for cellular interactions during Drosophila development. Development 117: 493-507.

Lieber, T., S. Kidd, E. Alcamo, V. Corbin, and M.W. Young. 1993. Antineurogenic phenotypes induced by truncated Notch proteins indicate a role in signal transduction and may point to a novel function for Notch in nuclei. Genes \& Dev. 7: 1949-1965.

Lindsell, C.E., C.J. Shawber, J. Boulter, and G. Weinmaster. 1995. Jagged: A mammalian ligand that activates Notchl. Cell 80: 909-917.

Lindsley, D.L. and G.G. Zimm. 1992. The genome of Drosophila melanogaster. Academic Press, San Diego, CA.

Meinhardt, H. 1983. Cell determination boundaries as organizing regions for secondary embryonic fields. Dev. Biol. 96: 375-385.

Muskavitch, M.A.T. 1994. Delta-Notch signaling and Drosophila cell fate choice. Dev. Biol. 166: 415-430.

Parks, A.L. and M.A.T. Muskavitch. 1993. Delta function is required for bristle organ determination and morphogenesis in Drosophila. Dev. Biol. 157: 484-496.

Parody, T.R. and M.A.T. Muskavitch. 1993. The pleiotropic function of Delta during postembryonic development of Drosophila melanogaster. Genetics 135: 527-539.

Parr, B.A. and A.P. McMahon. 1995. Dorsalizing signal Wnt-7a required for normal polarity of D-V and A-P axes of mouse limb. Nature 374: 350-353.

Patel, N.H., E. Martin-Blanco, K.G. Coleman, S.J. Poole, M.C. Ellis, T.B. Kornberg, and C.S. Goodman. 1989. Expression of engrailed proteins in arthropods, annelids, and chordates. Cell 58: 955-968.

Perrimon, N. 1995. Hedgehog and beyond. Cell 80: 517-520.

Phillips, R.G., and J.R.S. Whittle. 1993. wingless expression mediates determination of peripheral nervous system elements in late stages of Drosophila wing disc development. Development 118: 427-438.

Posakony, L.G., L.A. Raftery, and W.M. Gelbart. 1990. Wing formation in Drosophila melanogaster requires decapentaplegic gene function along the anterior-posterior compart ment. Mech. Dev. 33: 69-82.

Rebay, I., R.J. Fleming, R.G. Fehon, L. Cherbas, P. Cherbas, and S. Artavanis-Tsakonas. 1991. Specific EGF repeats of Notch mediate interactions with Delta and Serrate: Implications for Notch as a multifunctional receptor. Cell 67: 687-699.

Rebay, I., R.G. Fehon, and S. Atavanis-Tsakonas. 1993. Specific truncations of Drosophila Notch define dominant activated and dominant negative forms of the receptor. Cell 74: 319329.

Riddle, R.D., M. Ensini, C. Nelson, T. Tsuchida, T.M. Jessell, and C. Tabin. 1995. Induction of the LIM homeobox gene Lmx 1 by WNT7a establishes dorsoventral pattern in the vertebrate limb. Cell 83: 631-640.

Rulifson, E.J., and S.S. Blair. 1995. Notch regulates wingless expression and is not required for paracrine wingless signalling during wing margin neurogenesis in Drosophila. Devel- 


\section{Doherty et al.}

opment 121: 2813-2824.

Schweisguth, F. and J.W. Posakony. 1992. Suppressor of Hairless, the Drosophila homolog of the mouse recombination signal-binding protein gene, controls sensory organ cell fates. Cell 69: 1199-1212.

Shellenbarger, D.L. and J.D. Mohler. 1978. Temperature-sensitive periods and autonomy of pleiotropic effects on the $1(1) N^{t s 1}$, a conditional Notch lethal in Drosophila. Dev. Biol. 62: $432-446$.

Siegfried, E. and N. Perrimon. 1994. Drosophila wingless: A paradigm for the function and mechanism of Wnt signaling. BioEssays 16: 395-404.

Speicher, S.A., U. Thomas, U. Hinz, and E. Knust. 1994. The Serrate locus of Drosophila and its role in morphogenesis of the wing imaginal discs: Control of cell proliferation. Development 120: $535-544$.

Struhl, G. and K. Basler. 1993. Organizing activity of wingless protein in Drosophila. Cell 72: 527-540.

Struhl, G., K. Fitzgerald, and I. Greenwald. 1993. Intrinsic activity of the lin-12 and Notch intracellular domains in vivo. Cell 75: 331-345.

Tabata, T. and T.B. Kornberg. 1994. Hedgehog is a signaling protein with a key role in patterning Drosophila imaginal discs. Cell 76: 89-102.

Tabin, C. 1995. The initiation of the limb bud: Growth factors, Hox genes, and retinoids. Cell 80: 671-674.

Vaessin, H., K. Bremer, E. Knust, and J.A. Campos-Ortega. 1987. The neurogenic gene Delta of Drosophila melanogaster is expressed in neurogenic territories and encodes a putative transmembrane protein with EGF-like repeats. EMBO $I$. 6: 3431-3440.

van den Heuvel, M., R. Nusse, P. Johnston, and P.A. Lawrence. 1989. Distribution of the wingless gene product in Drosophila embryos: A protein involved in cell-cell communication. Cell 59: 739-749.

Whittle, J.R. 1990. Pattern formation in imaginal discs. Semin. Cell Biol. 1: 241-252.

Williams, J.A., J.B. Bell, and S.B. Carroll. 1991. Control of Drosophila wing and haltere development by the nuclear vestigial gene product. Genes \& Dev. 5: 2481-2495.

Williams, J.A., S. W. Paddock, and S.B. Carroll. 1993. Pattern formation in a secondary field: A hierarchy of regulatory genes subdivides the developing Drosophila wing disc into discrete subregions. Development 117: 571-584.

Williams, J.A., S.W. Paddock, K. Vorwerk, and S.B. Carroll. 1994. Organization of wing formation and induction of a wing-patterning gene at the dorsal/ventral compartment boundary. Nature 368: 299-305.

$\mathrm{Xu}, \mathrm{T}$. and G.M. Rubin. 1993. Analysis of genetic mosaics in developing and adult Drosophila tissues. Development 117: 1223-1237. 


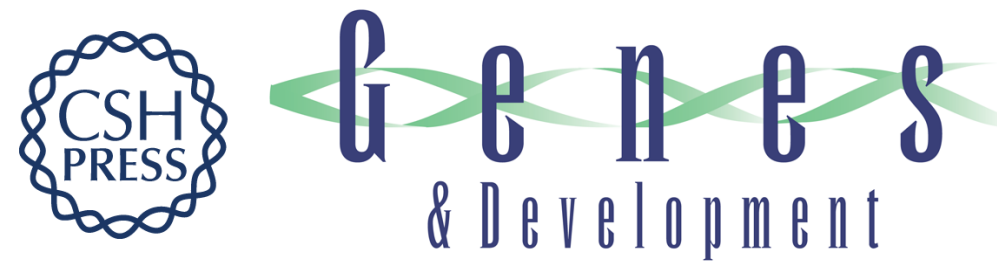

\section{Delta is a ventral to dorsal signal complementary to Serrate, another Notch ligand, in Drosophila wing formation.}

D Doherty, G Feger, S Younger-Shepherd, et al.

Genes Dev. 1996, 10:

Access the most recent version at doi:10.1101/gad.10.4.421

References This article cites 66 articles, 25 of which can be accessed free at: http://genesdev.cshlp.org/content/10/4/421.full.html\#ref-list-1

License

Email Alerting

Service

Receive free email alerts when new articles cite this article - sign up in the box at the top right corner of the article or click here.

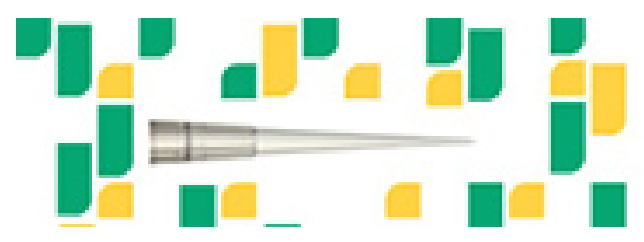

Focused on your science.

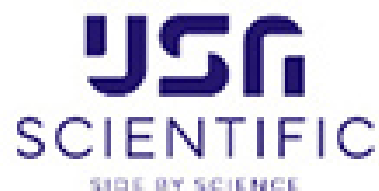

Copyright (c) Cold Spring Harbor Laboratory Press 